\title{
Inhibitive effect of Cocon nucifera L. (coconut pulp) extract on mild steel acid corrosion
}

\begin{abstract}
In recent years, industrial sectors are concerned with the corrosion of metal and alloys and they also received huge attention from researcher to overcome these problems. To decelerate the rate of corrosion or to stop the corrosion to occur, one of the common methods to deal with this problems is using green inhibitor. The use of local wastes which are organic in nature for the production of green corrosion inhibitor is no doubt the trend of the day. To arrive at an inexpensive non-toxic, eco-friendly inhibitor formulation, the present study on the use of coconut pulp waste extract of Cocon Nucifera L. has been carried out by the weight loss method. The aim of this project is to study the inhibitive effect in terms of time and concentration of the coconut pulp waste extract on the acid corrosion of mild steel in $1.0 \mathrm{M}$ HCL solution. Result showed that the inhibition efficiency was found to increase with increasing inhibitor concentration up to maximum $94.52 \%$ for $10 \% \mathrm{v} / \mathrm{v}$ at 48 hours immersion time. Examination on the extract by Fourier transform infrared spectroscopy (FTIR) confirms that the extract contains functional group of $\mathrm{N}-\mathrm{H}, \mathrm{O}-\mathrm{H}, \mathrm{C}-\mathrm{H}, \mathrm{Cf} \mathrm{C}, \mathrm{C}=\mathrm{O}$, $\mathrm{C}=\mathrm{C}, \mathrm{C}-\mathrm{F}$ and $\mathrm{C}-\mathrm{O}$ that good for corrosion inhibitor while scanning electron microscopy (SEM) studies showed that the deposition of coconut pulp extract on the metal surface. The results of all studies confirmed that the extract of coconut pulp has great potential to prevent the corrosion of mild steel in acidic environment with highest \% IE is $94.52 \%$ and the corrosion rate is $3.6919 \times 10-5$.
\end{abstract}

Keyword: Mild steel; Coconut pulp extract; Acid corrosion; Weight loss; Corrosion inhibition 